\title{
The Relationship between Depression, Anxiety, Somatization, Personality and Symptoms of Lower Urinary Tract Symptoms Suggestive of Benign Prostatic Hyperplasia
}

\author{
Jun Sung Koh${ }^{1}$, Hyo Jung Ko², Sheng-Min Wang ${ }^{3}$, Kang Joon Cho', \\ Joon Chul Kim¹, Soo-Jung Lee ${ }^{3}$, and Chi-Un Pae ${ }^{3,4} \bowtie$ \\ ${ }^{1}$ Department of Urology, The Catholic University of Korea College of Medicine, Seoul, Republic of Korea \\ 2Department of Psychiatry, Seoul Metropolitan Eunpyeong Hospital, Seoul, Republic of Korea \\ ${ }^{3}$ Department of Psychiatry, The Catholic University of Korea College of Medicine, Seoul, Republic of Korea \\ ${ }^{4}$ Department of Psychiatry and Behavioral Sciences, Duke University Medical Center, Duram, NC, USA
}

\begin{abstract}
This study investigated the relationship of personality, depression, somatization, anxiety with lower urinary tract symptoms suggestive of benign prostatic hyperplasia (LUTS/BPH). The LUTS/BPH patients were evaluated with the International Prostate Symptom Score (IPSS), 44-item Big Five Inventory (BFI), the Patient Health Questionnaire-9 (PHQ-9), the PHQ-15, and 7-item Generalized Anxiety Disorder Scale (GAD-7). The LUTS/BPH symptoms were more severe in patients with depression $(\mathrm{p}=0.046)$ and somatization $(\mathrm{p}=0.024)$, respectively. Neurotic patients were associated with greater levels of depression, anxiety and somatisation $(\mathrm{p}=0.0059, \mathrm{p}=0.004$ and $\mathrm{p}=0.0095$, respectively). Patients with high extraversion showed significantly low depression $(\mathrm{p}=0.00481)$ and anxiety ( $\mathrm{p}=0.035)$ than those with low extraversion. Our exploratory results suggest patients with LUTS/BPH may need careful evaluation of psychiatric problem including depression, anxiety and somatization. Additional studies with adequate power and improved designs are necessary to support the present exploratory findings.

Psychiatry Investig 2015;12(2):268-273
\end{abstract}

Key Words Lower urinary tract symptoms, Benign prostatic hyperplasia, Personality trait, Depression, Somatization, Clinical variable.

\section{INTRODUCTION}

Lower urinary tract symptoms (LUTS) consist of storage (frequency, urgency, and nocturia), voiding (poor stream, hesitancy, and straining to void), and post-micturition (terminal dribbling and incomplete emptying) difficulties and are common among older men. ${ }^{1}$ Of the various aetiologies and clinical symptoms associated with LUTS, benign prostatic hyperplasia (BPH) is considered a primary cause and can closely resemble its symptoms; however, a clear relationship between LUTS and BPH has yet to be fully elucidated..$^{1-3}$

Received: January 28, 2014 Revised: April 2, 2014

Accepted: April 12, 2014 Available online: December 12, 2014

$\triangle$ Correspondence: Chi-Un Pae, MD

Department of Psychiatry, Bucheon St. Mary's Hospital, The Catholic University of Korea College of Medicine, 327 Sosa-ro, Wonmi-gu, Bucheon 420-717, Republic of Korea

Tel: +82-32-340-7067, Fax: +82-32-340-2255, E-mail: pae@catholic.ac.kr

(c) This is an Open Access article distributed under the terms of the Creative Commons Attribution Non-Commercial License (http://creativecommons.org/licenses/by$\mathrm{nc} / 3.0$ ) which permits unrestricted non-commercial use, distribution, and reproduction in any medium, provided the original work is properly cited.
Despite the fact that LUTS and BPH (LUTS/BPH) are not considered life-threatening conditions, numerous large and well-designed cohort studies have demonstrated a diverse array of adverse impacts on personal and public health, including mental health..$^{4-9}$ LUTS/BPH is strongly associated with psychiatric disturbances such as depression, anxiety, and stress vulnerability, and impairments of instrumental activities during daily living. ${ }^{4-710-13}$ In fact, according to a very large recent cross-sectional, population-based, multi-national survey study, ${ }^{7}$ the negative effects of LUTS are prominent across overall perception of general health status and mental health. Additionally, a prevailing trend toward anxiety and depression was also observed in almost $30 \%$ of the other LUTS subgroup populations. However, Korean LUTS/BPH data regarding depression, anxiety and somatisation is still lacking, in particular personality-related researches have not been studied across the world. ${ }^{14}$

Hence, we tried to investigate the relationship between depression, anxiety, somatisation, personality and LUTS/BPH in Korean patients, with the use of validated brief rating scales. 
It was hypothesised that depression, anxiety and somatisation would influence of symptoms of LUTS/BPH. In addition, personality traits may be associated with clinical characteristics including the severity of LUTS/BPH since one's personality profile may be a crucial factor to given stressors and/or diseases. $^{15-17}$

\section{METHODS}

\section{Subjects}

Male patients with LUTS/BPH were recruited at an outpatient clinic in the Department of Urology at Bucheon St. Mary's Hospital.

Principal inclusion criteria included men aged $\geq 40$ years, a clinical diagnosis of LUTS/BPH was evaluated by medical history, assessment of symptoms and bother, a careful physical examination, digital rectal examination, and laboratory tests such as urinalysis and prostate-specific antigen (PSA) level. Few exclusion criteria were applied because the aims of the study were based on an observational approach. However, patients who exhibited the following symptoms were excluded for diagnostic stability: 1) PSA level $>10 \mathrm{ng} / \mathrm{mL}, 2$ ) a history or evidence of prostate cancer by prostate biopsy, 3) previous prostatic surgery, 4) neurogenic bladder by neurological disorders such as multiple sclerosis, Parkinson's disease, spinal cord injury and spina bifida, which was based on the results from physical examination focusing on both the status of the patient's neurologic system and pelvic anatomy, and neurologic examination focusing on mental status, strength, sensation and neuronal reflexes, and urodynamic evaluations, 5) bladder stone, 6) bladder neck contracture, 7) urethral stricture, 8) bladder malignancy, 9) acute or chronic prostatitis, 10) acute, chronic or recurrent urinary tract infections, 11) any possible causes presenting LUTS other than $\mathrm{BPH}$, and 12) speech or language deficits and cognitive dysfunction.

The present protocol was approved by the Institutional Review Board of Bucheon St. Mary's Hospital.

\section{Clinical outcomes}

\section{Rating scales}

This study utilised all the Korean versions of the International Prostate Symptom Score (IPSS) for severity of LUTS/ $\mathrm{BPH},{ }^{18}$ the Patient Health Questionnaire-9 (PHQ-9) for depression, ${ }^{19,20}$ the Patient Health Questionnaire-15 (PHQ-15) for somatization, ${ }^{21,22}$ the 7-item Generalized Anxiety Disorder Scale (GAD-7) ${ }^{23}$ for anxiety and the 44-item Big Five Inventory (BFI) for personality. ${ }^{24,25}$ The criteria for depression $(\geq 5$ on PHQ-9), ${ }^{19}$ anxiety ( $\geq 5$ on GAD-7 $)^{23}$ and somatisation ( $\geq 5$ on PHQ-15) ${ }^{21}$ were defined by previously suggested ones.
The BFI personality traits consist of the following: extraversion (E), agreeableness $(\mathrm{A})$, conscientiousness $(\mathrm{C})$, neuroticism $(\mathrm{N})$ and openness $(\mathrm{O})$. The BFI, which was developed based on the Five Factor Model (FFM), consists of 44 items for which higher scores represent higher levels of each personality trait. ${ }^{23}$ Each personality trait domain was categorised into low $(\mathrm{L})$ and high $(\mathrm{H})$ groups according to median values, as described in a previous study. ${ }^{26}$

\section{Statistical analyses}

Demographic and clinical variables are described and also compared according to each personality trait and other parameters using the Student's t-test, chi-square test with Yate's correction, or Fisher's test where appropriate. Statistical significance was two-tailed and set at $\mathrm{p}<0.05$. All statistical analyses were conducted using the NCSS $2007^{\circledR}$ and PASSP ${ }^{\circledR}$ (Kaysville, Utah, USA).

\section{RESULTS}

\section{Clinical and demographic characteristics}

Ninety three patients participated in the study. The mean age of the whole population was approximately $62(61.7 \pm 8.0)$ years, and the majority of patients were married. More than half of patients exhibited comorbid medical diseases. The mean total score on the IPSS among all groups was approximately 17 , indicating a moderate severity of LUTS/BPH symptoms.

There were no group differences in IPSS total scores, education level, family history of LUTS/BPH, economic status, duration of disease, medications, comorbidity, alcohol history, smoking history, or marriage status according to each personality domain (data available on request). These trends were also observed when we divide the patients according to presence/absence of depression, anxiety and somatisation (data available on request).

The LUTS/BPH symptoms were more severe in patients with depression $(\mathrm{p}=0.046)$ and somatization $(\mathrm{p}=0.024)$, respectively, while anxiety did not correlated with symptoms of LUTS/BPH (Table 1). However, anxious patients showed numerically higher LUTS/BPH symptoms than nonanxious patients.

\section{Neuroticism}

Mean total scores on the PHQ-9, GAD-7, and PHQ-15 were 1.7, 1.7 and 1.6 fold higher, respectively, in high neuroticism (HN) compared to low neuroticism (LN) ( $\mathrm{p}=0.0059$, $\mathrm{p}=0.004$ and $\mathrm{p}=0.0095$ ) (Table 2 ). The proportion of depression $\left(52.3 \%\right.$ vs. $\left.24.5 \%, \chi^{2}=7.624, \mathrm{p}=0.01\right)$ and anxiety $(56.8 \%$ vs. $26.5 \%, \chi^{2}=8.801, p=0.003$ ) was significantly higher in $\mathrm{HN}$ 
than in LN. The No other characteristics were significantly different between these groups (Table 2).

\section{Extraversion, agreeableness, conscientiousness, and openness groups}

Patients with high extraversion (HE) showed significantly low depression ( $\mathrm{p}=0.00481)$ and anxiety $(\mathrm{p}=0.035)$ than those with low extraversion (LE). Otherwise, there were no significant differences among the remaining variables between the high and low groups in the other personality domains (Table 2).

\section{DISCUSSION}

According to our study, patients with depression and somatisation showed higher level of LUTS/BPH symptoms; anxious patients showed a numerically higher LUTS/BPH symptoms. Additionally, $\mathrm{HN}$ was associated with greater levels of depression, anxiety and somatisation. The proportion of depression and anxiety was also significantly higher in $\mathrm{HN}$ group than in LN. The mean PHQ-9 and GAD-7 total scores were significantly higher in LE group than in HE group. Other personality traits were not associated with other clinical characteristics in LUTS/BPH patients. The strength of the present study includes a comprehensive evaluation of the relationship between symptomatology of LUTS/BPH and depression, somatisation, anxiety and personality traits. Additionally, this study employed simple, quick, reliable, wellvalidated, and self-administered personality scales, which is easy to interpret, even in a busy routine practice.

Previous studies have mainly focused on the negative effect of LUTS on quality of life, overall perception of bladder problems, general health status and mental health. ${ }^{7,11,12}$ In such studies, the high level of psychiatric morbidity was consistently demonstrated. In this context, an intriguing point is that we conversely investigated the influence of depression, anxiety, somatization and personality on the manifestation of LUTS/BPH symptoms. Pre-existing study results and our findings suggest that putative role of psychiatric parameters in the development of LUTS/BPH and proposes that the current treatment for LUTS/BPH may not fully ameliorate urinary issues if the underlying psychiatric disturbances are not properly resolved. ${ }^{27}$ Hence, proper evaluation and management of depression, anxiety and somatization has important implications for the appropriate management of patients with

Table 1. The IPSS total scores and severity distribution of LUTS/BPH by presence/absence of depression, anxiety and somatization

\begin{tabular}{|c|c|c|c|c|c|c|}
\hline & \multicolumn{2}{|c|}{ Depression } & \multicolumn{2}{|c|}{ Anxiety } & \multicolumn{2}{|c|}{ Somatization } \\
\hline & Presence & Absence & Presence & Absence & Presence & Absence \\
\hline IPSS total & $18.5 \pm 6.9$ & $15.3 \pm 7.9^{*}$ & $17.7 \pm 6.5$ & $15.6 \pm 8.3$ & $18.3 \pm 7.3$ & $14.7 \pm 7.6^{\dagger}$ \\
\hline \multicolumn{7}{|l|}{ Severity of UTS/BPH } \\
\hline Mild to moderate & $21(60.0)$ & $41(70.7)$ & $24(63.2)$ & $38(69.1)$ & $29(63.0)$ & $33(70.2)$ \\
\hline Severe & $14(40.0)$ & $17(29.3)$ & $14(36.8)$ & $17(30.9)$ & $17(37.0)$ & $14(29.8)$ \\
\hline Total number & $35(100.0)$ & $58(100.0)$ & $38(100.0)$ & $55(100.0)$ & $46(100.0)$ & $47(100.0)$ \\
\hline
\end{tabular}

Data represent mean \pm standard deviation or number (\%). IPSS: International Prostate Symptom Score, LUTS/BPH: lower urinary tract syndrome/benign prostate hyperplasia, mild $(0-7)$, moderate $(8-19)$ and severe $(\geq 20)$ in IPSS; ${ }^{p} \mathrm{p}=0.046,{ }^{\dagger} \mathrm{p}=0.024$ based on Student $\mathrm{t}$-test; The criteria for depression ( $\geq 5$ on Patient Health Questionnaire-9, PHQ-9), anxiety ( $\geq 5$ on Generalized Anxiety Disorder Assessment item-7, GAD-7) and somatisation ( $\geq 5$ on PHQ-15)

Table 2. Clinical characteristics of the sample based on personality profiles ( $N=93)$

\begin{tabular}{|c|c|c|c|c|c|c|c|c|c|c|}
\hline & \multicolumn{2}{|c|}{ Neuroticism } & \multicolumn{2}{|c|}{ Extraversion } & \multicolumn{2}{|c|}{ Agreeableness } & \multicolumn{2}{|c|}{ Conscientiousness } & \multicolumn{2}{|c|}{ Openness } \\
\hline & $\begin{array}{c}\text { High } \\
(\mathrm{N}=44)\end{array}$ & $\begin{array}{c}\text { Low } \\
(\mathrm{N}=49)\end{array}$ & $\begin{array}{c}\text { High } \\
(\mathrm{N}=38)\end{array}$ & $\begin{array}{c}\text { Low } \\
(\mathrm{N}=55)\end{array}$ & $\begin{array}{l}\text { High } \\
(\mathrm{N}=39)\end{array}$ & $\begin{array}{c}\text { Low } \\
(\mathrm{N}=54)\end{array}$ & $\begin{array}{c}\text { High } \\
(\mathrm{N}=37)\end{array}$ & $\begin{array}{c}\text { Low } \\
(\mathrm{N}=56)\end{array}$ & $\begin{array}{l}\text { High } \\
(\mathrm{N}=41)\end{array}$ & $\begin{array}{c}\text { Low } \\
(\mathrm{N}=52)\end{array}$ \\
\hline IPSS total & $16.5 \pm 7.6$ & $16.4 \pm 7.7$ & $15.4 \pm 7.4$ & $17.2 \pm 7.8$ & $15.3 \pm 17.5$ & $17.4 \pm 8.2$ & $16.8 \pm 7.8$ & $16.4 \pm 7.6$ & $15.7 \pm 7.7$ & $17.1 \pm 7.7$ \\
\hline IPSS-Obs & $9.8 \pm 5.0$ & $10.1 \pm 5.3$ & $9.5 \pm 5.4$ & $10.3 \pm 4.9$ & $9.5 \pm 4.8$ & $10.3 \pm 5.4$ & $10.6 \pm 5.0$ & $9.6 \pm 5.2$ & $9.7 \pm 5.6$ & $10.2 \pm 4.8$ \\
\hline IPSS-Sto & $6.7 \pm 3.7$ & $6.4 \pm 3.6$ & $5.9 \pm 3.1$ & $5.9 \pm 3.1$ & $5.8 \pm 3.4$ & $7.0 \pm 3.7$ & $6.1 \pm 4.1$ & $6.8 \pm 3.3$ & $6.0 \pm 3.2$ & $7.0 \pm 3.9$ \\
\hline IPSS-QoL & $3.5 \pm 1.4$ & $3.4 \pm 1.5$ & $3.2 \pm 1.6$ & $3.6 \pm 1.4$ & $3.4 \pm 1.6$ & $3.5 \pm 1.4$ & $3.7 \pm 1.3$ & $3.3 \pm 1.6$ & $3.2 \pm 1.6$ & $3.7 \pm 1.3$ \\
\hline PHQ-9 & $5.8 \pm 4.4$ & $3.4 \pm 3.8^{*}$ & $3.5 \pm 3.1$ & $5.2 \pm 4.8^{\dagger}$ & $3.8 \pm 4.0$ & $5.1 \pm 4.4$ & $3.7 \pm 3.2$ & $5.1 \pm 4.8$ & $4.1 \pm 4.4$ & $4.9 \pm 4.2$ \\
\hline PHQ-15 & $6.3 \pm 4.9$ & $4.0 \pm 3.4^{\ddagger}$ & $4.2 \pm 3.1$ & $5.7 \pm 4.9$ & $4.7 \pm 5.2$ & $5.4 \pm 3.6$ & $4.8 \pm 3.5$ & $5.4 \pm 4.7$ & $4.5 \pm 4.2$ & $5.6 \pm 4.3$ \\
\hline GAD-7 & $5.6 \pm 4.1$ & $3.4 \pm 3.6^{\S}$ & $3.4 \pm 3.0$ & $5.2 \pm 4.5^{\| \prime}$ & $3.9 \pm 3.7$ & $4.9 \pm 4.2$ & $3.8 \pm 3.1$ & $4.9 \pm 4.5$ & $4.0 \pm 4.1$ & $4.9 \pm 3.9$ \\
\hline
\end{tabular}

Data represent mean \pm standard deviation. ${ }^{*} \mathrm{p}=0.0059,{ }^{\dagger} \mathrm{p}=0.0481,{ }^{\ddagger} \mathrm{p}=0.0095,{ }_{\mathrm{p}} \mathrm{p}=0.004,{ }^{1} \mathrm{p}=0.035$ based on Student t-test. IPSS: International Prostate Symptom Score, Obs: obstruction, sto: storage, QoL: quality of life, PHQ: Patient Health Questionnaire, GAD-7: Generalized Anxiety Disorder Assessment item 7 
multiple facets of LUTS/BPH and also warrants further indepth studies regarding the specific mechanisms underlying such relationship.?

When the personality traits of our patients were compared with norm levels from 56 nations, $\mathrm{O}, \mathrm{A}, \mathrm{C}$ and $\mathrm{E}$ were relatively low. ${ }^{28}$ This potentially point out LUTS/BPH patients may have differential pattern of personality profile compared with healthy controls. In fact, the trait nature of one's personality profile is supported by the findings from a 2-year observation of illness behaviour and personality changes in patients with chronic prostatitis. ${ }^{29}$ In such study, the subjective well-being of patients was impaired, but the personality of patients did not change during the course of the investigation. ${ }^{29}$ However, $\mathrm{N}$ was lower than norm levels in the present study, in contrast to the hypothesis. According to a study investigating the development of personality traits, ${ }^{30} \mathrm{C}$ and $\mathrm{A}$ tend to increase with aging, whereas $\mathrm{N}, \mathrm{O}$, and $\mathrm{E}$ decrease with aging. These findings are in line with our results based on our elderly population under investigation (mean age= 61.7 years), also partly explaining why our patients have a relatively low level of $\mathrm{N}$ compared to the norm of healthy population.

$\mathrm{N}$ is highly correlated with various psychological factors such as anxiety, depression, pessimistic attitudes, hopelessness, impulsivity, hostility, low self-esteem, anger and vulnerability to stress and chronic negative emotions. ${ }^{28}$ Such psychiatric disturbances are also associated with symptoms and clinical outcomes of LUTS/BPH. ${ }^{11,12,27,31-35}$

The depression and anxiety symptoms were significantly higher in LE than in HE group. E was found to be highly correlated with self-efficacy as well as depression and anxiety. ${ }^{3,28,36}$ Additionally, E bears a higher tendency to experience emotional positivity, energy, sociability, and warmth, is positively correlated with self-esteem and adaptive coping styles, and is negatively correlated with trait anxiety and the fear of negative evaluation. These are all critical psychological factors that influence the course of LUTS/BPH. ${ }^{28}$ Therefore, our present findings put the pieces of relationship between psychological factors and $\mathrm{E}$ together. Hence, the present results may substantiate the importance of pre-assessment to determine whether a LUTS/BPH patient is neurotic in order to prudently predict clinical course.

However, other personality traits such as A, C, and O were not significantly associated with clinical characteristics in LUTS/BPH patients, although numerically lower tendency toward severe symptoms of LUTS/BPH in lower A, C, and O groups were consistent. $\mathrm{A}$ is associated with a greater amount of social support, the improvement of depression/anxiety, and better adaptive coping styles, ${ }^{28,37,38}$ even in patients with severe medico-surgical conditions. ${ }^{39-41} \mathrm{C}$ is positively associated with global and family life function as well as work productivity, self-efficacy, and QoL. ${ }^{3,38} \mathrm{O}$ is also associated with positive emotions, subjective happiness, and a desire for new challenge as well as an intellectual, imaginative, and independentminded attitude. ${ }^{27,42,43}$ Therefore, we could not fully exclude a possibility of potential relationship between LUTS/BPH symptoms and personality profiles of $\mathrm{A}, \mathrm{C}$, and $\mathrm{O}$, although such personality traits were not significantly associated with the clinical characteristics in LUTS/BPH patients in the present study.

We failed to show a global relationship between all five personality traits and LUTS/BPH symptoms severity. This point should be more investigated in future studies. We may assume that the BFI may not be relevant or sensitive to find such relationship. Additionally, the intricate and interactive relationship between personality and the disease itself should not be excluded. Several studies have suggested that LUTS/BPH itself may potentially result in personality changes. ${ }^{44}$ Therefore, the present results may not exclusively reflect premorbid personality traits because this study was unable to assess the personality profiles of patients before they were diagnosed with LUTS/BPH. The small sample size may be insufficient to detect such relationship between personality and symptom severity of LUTS/BPH. Currently, there are no large and unselected population-based studies that have utilised the BFI on patients with LUTS/BPH, and thus, the current results are entirely preliminary. The use of brief self-rating scales may be one of strength to be utilized in busy clinical practice but also could be a critical limitation; we propose to use of both subjective and objective rating scale to verify depression, anxiety and somatization as well as including some assessment of current burden of stress. We have to also consider inherent limitations of the BFI as followings: ${ }^{45} 1$ ) a failure of full explanation about all of human personality; 2) a failure to include privately held or more context-dependent personality; 3) dependent relationship between the five personality traits potentially resulting in redundancy between the dimensions; 4) a failure to predict to specific human behaviour; 5) inability to address core constructs of personality functioning beyond the level of personality trait; 6) lack of conditional nature of human experience; 7) mainly rely on simple, non-contingent and comparative statement about person; and 8) not an integrative assessment. The sample was only recruited in one teaching hospital leading to some critical limitations (i.e., poor generalization of the results, lack of representativeness of LUTS/ BPH population, an increased likelihood of inclusion of selected patient population, local area own bias, e.t.c.). Finally, the causal relationships between psychiatric and urinary symptoms have yet to be determined. Indeed, the pathophysiology of the relationship between them and such significance 
in clinical practice still remain unclear, indicating a need of more extensive researches in this area. Hence, this issue should be fully addressed in adequately-powered and well-designed studies near future.

In conclusion, our exploratory results suggest patients with LUTS/BPH may need careful evaluation of psychiatric problem including depression, anxiety and somatization. Additional studies with adequate power and improved designs are necessary to support the present exploratory findings.

\section{Acknowledgments}

This study was partially funded by the Ministry of Health and Welfare, Republic of Korea (HI12C0003).

\section{REFERENCES}

1. Madersbacher S, Alivizatos G, Nordling J, Sanz CR, Emberton M, de la Rosette JJ. EAU 2004 guidelines on assessment, therapy and follow-up of men with lower urinary tract symptoms suggestive of benign prostatic obstruction (BPH guidelines). Eur Urol 2004;46:547-554.

2. Abrams P, Chapple C, Khoury S, Roehrborn C, de la Rosette J; International Consultation on New Developments in Prostate Cancer and Prostate Diseases. Evaluation and treatment of lower urinary tract symptoms in older men. J Urol 2013;189(1 Suppl):S93-S101.

3. Speakman MJ. Lower urinary tract symptoms suggestive of benign prostatic obstruction: what is the available evidence for rational management? Eur Urol 2001;39(Suppl 3):6-12.

4. Parsons JK. Benign prostatic hyperplasia and male lower urinary tract symptoms: epidemiology and risk factors. Curr Bladder Dysfunct Rep 2010;5:212-218.

5. Taylor BC, Wilt TJ, Fink HA, Lambert LC, Marshall LM, Hoffman AR, et al. Prevalence, severity, and health correlates of lower urinary tract symptoms among older men: the MrOS study. Urology 2006;68:804809.

6. Kupelian V, Wei JT, O'Leary MP, Kusek JW, Litman HJ, Link CL, et al. Prevalence of lower urinary tract symptoms and effect on quality of life in a racially and ethnically diverse random sample: the Boston Area Community Health (BACH) Survey. Arch Intern Med 2006;166:23812387.

7. Coyne KS, Wein AJ, Tubaro A, Sexton CC, Thompson CL, Kopp ZS, et al. The burden of lower urinary tract symptoms: evaluating the effect of LUTS on health-related quality of life, anxiety and depression: EpiLUTS. BJU Int 2009;103(Suppl 3):4-11.

8. Irwin DE, Milsom I, Kopp Z, Abrams P, Artibani W, Herschorn S. Prevalence, severity, and symptom bother of lower urinary tract symptoms among men in the EPIC study: impact of overactive bladder. Eur Urol 2009;56:14-20.

9. Irwin DE, Milsom I, Hunskaar S, Reilly K, Kopp Z, Herschorn S, et al. Population-based survey of urinary incontinence, overactive bladder, and other lower urinary tract symptoms in five countries: results of the EPIC study. Eur Urol 2006;50:1306-1314; discussion 1314-1315.

10. Robertson C, Link CL, Onel E, Mazzetta C, Keech M, Hobbs R, et al. The impact of lower urinary tract symptoms and comorbidities on quality of life: the BACH and UREPIK studies. BJU Int 2007;99:347354.

11. Rom M, Schatzl G, Swietek N, Rucklinger E, Kratzik C. Lower urinary tract symptoms and depression. BJU Int 2012;110:E918-E921.

12. Wong SY, Hong A, Leung J, Kwok T, Leung PC, Woo J. Lower urinary tract symptoms and depressive symptoms in elderly men. J Affect Disord 2006;96:83-88

13. Glover L, Gannon K, McLoughlin J, Emberton M. Men's experiences of having lower urinary tract symptoms: factors relating to bother. BJU Int 2004;94:563-567.

14. Koh JS, Ko H, Wang SM, Cho K, Kim J, Lee, SJ, et al. Depression and somatic symptoms may influence on chronic prostatitis/chronic pelvic pain syndrome: a preliminary study. Psychiatry Investig 2014;11:495-498.

15. Coulston CM, Bargh DM, Tanious M, Cashman EL, Tufrey K, Curran $\mathrm{G}$, et al. Is coping well a matter of personality? A study of euthymic unipolar and bipolar patients. J Affect Disord 2013;145:54-61.

16. De Fazio P, Caroleo M, Rizza P, Cerminara G, De Serio D, Indolfi C, et al. Specific personality traits and coping styles predict affective symptoms in early post acute coronary syndrome inpatients. Int J Psychiatry Med 2012;44:119-132.

17. Powers AD, Oltmanns TF. Personality pathology as a risk factor for negative health perception. J Pers Disord 2013;27:359-370.

18. Choi HR, Chung WS, Shim BS, Kwon SW, Hong SJ, Chung BH, et al. Translation validity and reliability of I-PSS Korean version. Korean J Urol 1996;37:659-665.

19. Han C, Jo SA, Kwak JH, Pae CU, Steffens D, Jo I, et al. Validation of the Patient Health Questionnaire-9 Korean version in the elderly population: the Ansan Geriatric study. Compr Psychiatry 2008;49:218-223.

20. Kroenke K, Spitzer RL, Williams JB. The PHQ-9: validity of a brief depression severity measure. J Gen Intern Med 2001;16:606-613.

21. Han C, Pae CU, Patkar AA, Masand PS, Kim KW, Joe SH, et al. Psychometric properties of the Patient Health Questionnaire-15 (PHQ-15) for measuring the somatic symptoms of psychiatric outpatients. Psychosomatics 2009;50:580-585.

22. Kroenke K, Spitzer RL, Williams JB. The PHQ-15: validity of a new measure for evaluating the severity of somatic symptoms. Psychosom Med 2002;64:258-266.

23. Spitzer RL, Kroenke K, Williams JB, Lowe B. A brief measure for assessing generalized anxiety disorder: the GAD-7. Arch Intern Med 2006;166:1092-1097.

24. John OP, Srivastata S. The Big Five Trait Taxonomy: History, Measurement, and Theoretical Perspectives. In: Pervin LA, John OP, Editors. Handbook of Personality, 2nd Edition. New York: Guilford Press, 1999, p. 102-138.

25. Kim SY, Kim JM, Yoo JA, Bae KY, Kim SW, Yang SJ, et al. Standarization and validation of Big Five Inventory-Korean Version (BFI-K) in elders. Korean J Biol Psychiatry 2010;17:15-25.

26. Jerant A, Chapman B, Duberstein P, Franks P. Effects of personality on self-rated health in a 1-year randomized controlled trial of chronic illness self-management. Br J Health Psychol 2010;15:321-335.

27. Seyfried LS, Wallner LP, Sarma AV. Psychosocial predictors of lower urinary tract symptom bother in black men: the Flint Men's Health Study. J Urol 2009;182:1072-1077.

28. Schmitt DP, Allik J, McCrae RR, Benet-Martinez V. The geographic distribution of Big Five Personality Traits: patterns and profiles of human self-description across 56 nations. J Cross Cult Psychol 2007;38: 173-212.

29. Keltikangas-Jarvinen L, Mueller K, Lehtonen T. Illness behavior and personality changes in patients with chronic prostatitis during a twoyear follow-up period. Eur Urol 1989;16:181-184.

30. Srivastava S, John OP, Gosling SD, Potter J. Development of personality in early and middle adulthood: set like plaster or persistent change? J Pers Soc Psychol 2003;84:1041-1053.

31. Pond DA, Maratos J. Psychosocial inter-relations of benign prostatic hypertrophy. J Psychosom Res 1977;21:201-206.

32. Ullrich PM, Lutgendorf SK, Leserman J, Turesky DG, Kreder KJ. Stress, hostility, and disease parameters of benign prostatic hyperplasia. Psychosom Med 2005;67:476-482.

33. Engstrom G, Henningsohn L, Steineck G, Leppert J. Self-assessed health, sadness and happiness in relation to the total burden of symptoms from the lower urinary tract. BJU Int 2005;95:810-815.

34. Stone AA, Mezzacappa ES, Donatone BA, Gonder M. Psychosocial stress and social support are associated with prostate-specific antigen 
levels in men: results from a community screening program. Health Psychol 1999;18:482-486.

35. Hayward RD, Taylor WD, Smoski MJ, Steffens DC, Payne ME. Association of five-factor model personality domains and facets with presence, onset, and treatment outcomes of major depression in older adults. Am J Geriatr Psychiatry 2013;21:88-96.

36. Schrier AC, de Wit MA, Krol A, Fassaert TJ, Verhoeff AP, Kupka RW, et al. Similar associations between personality dimensions and anxiety or depressive disorders in a population study of Turkish-Dutch, Moroccan-Dutch, and native Dutch subjects. J Nerv Ment Dis 2013;201: 421-428.

37. Lee-Baggley D, Preece M, Delongis A. Coping with interpersonal stress: role of big five traits. J Pers 2005;73:1141-1180.

38. Chute CG, Panser LA, Girman CJ, Oesterling JE, Guess HA, Jacobsen SJ, et al. The prevalence of prostatism: a population-based survey of urinary symptoms. J Urol 1993;150:85-89.

39. Liber JM, Faber AW, Treffers PD, Van Loey NE. Coping style, personality and adolescent adjustment 10 years post-burn. Burns 2008;34:775-
782.

40. Hoth KF, Christensen AJ, Ehlers SL, Raichle KA, Lawton WJ. A longitudinal examination of social support, agreeableness and depressive symptoms in chronic kidney disease. J Behav Med 2007;30:69-76.

41. Kye SY, Park K. Psychosocial factors and health behavior among Korean adults: a cross-sectional study. Asian Pac J Cancer Prev 2012;13:4956.

42. Tkach C, Lyubomirsky S. How do people pursue happiness? Relating personality, happiness-increasing strategies, and well-being. J Happiness Stud 2006;7:183-225.

43. Shiota MN, Keltner D, John OP. Positive emotion dispositions differentially associated with big five personality and attachment style. J Posit Psychol 2006;1:61-71.

44. Kim SY, Kim JM, Stewart R, Kang HJ, Kim SW, Shin IS, et al. Influences of personality traits on quality of life after stroke. Eur Neurol 2013;69: 185-192.

45. McAdams DP. The five-factor model in personality: a critical appraisal. J Pers 1992;60:329-361. 